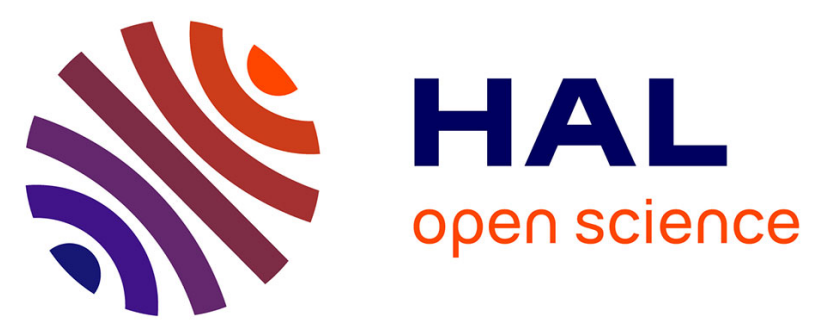

\title{
Polygyny and symmetric concurrency: comparing long-duration STI prevalence using simulated sexual networks
}

Shalini Santhakumaran, Katie O'Brien, Roel Bakker, Toby Ealden, Leigh Anne Shafer, Rhian M Daniel, Ruth Chapman, Richard J Hayes, Richard G White

\section{To cite this version:}

Shalini Santhakumaran, Katie O'Brien, Roel Bakker, Toby Ealden, Leigh Anne Shafer, et al.. Polygyny and symmetric concurrency: comparing long-duration STI prevalence using simulated sexual networks. Sexually Transmitted Infections, 2010, 86 (7), pp.553. 10.1136/sti.2009.041780 . hal00557468

\section{HAL Id: hal-00557468 \\ https://hal.science/hal-00557468}

Submitted on 19 Jan 2011

HAL is a multi-disciplinary open access archive for the deposit and dissemination of scientific research documents, whether they are published or not. The documents may come from teaching and research institutions in France or abroad, or from public or private research centers.
L'archive ouverte pluridisciplinaire HAL, est destinée au dépôt et à la diffusion de documents scientifiques de niveau recherche, publiés ou non, émanant des établissements d'enseignement et de recherche français ou étrangers, des laboratoires publics ou privés. 
The potential impact of polygyny on long-duration STI prevalence using simulated sexual networks

\section{Authors}

Santhakumaran, $\mathrm{S}^{1,2}$; O’Brien; $\mathrm{K}^{1}$; Bakker, $\mathrm{R}^{3,4}$; Ealden, $\mathrm{T}^{1}$; Shafer, $\mathrm{LA}^{5}$, Daniel, $\mathrm{RM}^{1}$; Chapman, $\mathrm{R}^{1}$; Hayes, $\mathrm{RJ}^{1}$; White, $\mathrm{RG}^{1}$.

\section{Corresponding author}

Dr Richard White, Infectious Disease Epidemiology Unit, Department of Epidemiology and Public Health, and Centre for the Mathematical Modelling of Infectious Diseases, London School of Hygiene and Tropical Medicine, Keppel Street, London WC1E 7HT. Tel: + $44(0)$ 2072994626 Email: richard.white@lshtm.ac.uk

Keywords: mathematical model, HIV, HSV 2, sexual behaviour, concurrency, polygamy

Abstract: 248 Main text: 2757 Figs: 3

\section{Authors' affiliations}

\footnotetext{
${ }^{1}$ Department of Epidemiology and Population Health, London School Of Hygiene and Tropical Medicine, London, UK

2 Department of Epidemiology, Public Health and Primary Care, Imperial College London, London, UK

3 Erasmus MC, University Medical Center Rotterdam, Rotterdam, The Netherlands

${ }^{4}$ Hogeschool Rotterdam, Rotterdam, The Netherlands

${ }^{5}$ Medical Research Council Programme on AIDS in Uganda, Uganda Virus Research Institute, Entebbe, Uganda
} 


\section{Abstract}

\section{Objective}

To compare the effects of polygyny (only males can form concurrent partnerships) and gender-symmetric concurrency (both genders can form concurrent partnerships) on prevalence of long-duration STIs using a dynamic stochastic network model.

\section{Methods}

We modelled two pairs of scenarios: polygyny and gender symmetry at higher and lower levels of network concurrency (measured by the average number of concurrent partnerships per partnership). The same level of sexual activity was modelled in all scenarios (measured by mean per-capita partnership incidence and per-capita number of sex-acts). Partnership duration and network concurrency were constant within each of the polygyny/symmetry pairs. Infections that mimicked characteristics of HSV2 and HIV were introduced onto the networks separately. The mean prevalence 100 years after introduction for the HSV2-like infection and 30 years after introduction for the HIV-like infection were calculated over 1000 model iterations.

\section{Results}

Prevalence of both simulated STIs was significantly lower in the polygyny scenarios than in the symmetry scenarios. At lower concurrency, polygyny resulted in a relative reduction in HSV2-like infection prevalence of $19 \%$ (95\% confidence interval= $15-23)$ compared to gender-symmetry. At higher concurrency polygyny led to a relative reduction of $20 \%(16-23)$. The relative reduction in prevalence of the HIV-like infection after 30 years was $14 \%(10-17)$ at lower concurrency and 8\% (5-11) at higher concurrency.

\section{Conclusions}

Polygyny can result in lower STI prevalence compared to populations where both genders practise concurrency. Further work is required to explore whether this reduction is observed when modelling more realistic populations and infection characteristics. 


\section{Introduction}

The burden of HIV/AIDS is disproportionately high in Sub-Saharan Africa. In 2008, the region accounted for $71 \%$ of all new HIV infections [1]. Concurrent sexual partnerships (overlapping partnerships with a partner in common) have been proposed as one explanation for the high prevalence of HIV infection in some countries [2, 3]. Modelling studies suggest the presence of concurrent sexual partnerships can increase the rate of invasion of STls [4-6], but empirical evidence is equivocal, partly due to difficulties in collecting information on and quantifying concurrency $[7,8]$.

In contrast, a recent multi-country empirical ecological analysis by Reniers and Watkins showed that HIV prevalence is lower in countries with higher levels of polygyny (a specific form of institutionalised concurrency where men have many wives but women are monogamous) [9]. This association remained after adjusting for confounding factors such as the level of male circumcision. A similar negative association was found in an earlier ecological empirical study in Malawi [10]. Although these associations may be due to the ecological inference fallacy [11] and therefore we cannot draw conclusions at the individual level, the difference between polygyny and symmetric concurrency relates to the structure of the network as a whole, rather than the behaviour of individuals, so examining data at the ecological level is appropriate. Reniers and Watkins suggest one possible causal explanation for this association: polygyny prevents the formation of larger groups of individuals connected by partnerships (also called current-partnership network components) compared to a situation in which both males and females can form concurrent partnerships [9].

In this study we explored the hypothesis that polygyny may lead to lower HIV prevalence compared to the scenario where both genders can form concurrent partnerships. We used a 
model to simulate the spread of two sexually transmitted infections (STIs) on a heterosexual partnership network in which (a) only males can form concurrent partnerships (polygyny), or (b) both males and females can form concurrent partnerships (gender-symmetric concurrency), while keeping the overall level of sexual activity in the simulated populations constant. 


\section{Methods}

The Mukwano network STI model

Mukwano is a dynamic, event-driven individual-based network model [12, 13] which simulates births and deaths, partnership formation and dissolution, and STI transmission in a population over a period of time. Events are modelled to occur sequentially using a calendar queue [14]. The input parameters are used to set demographic, behavioural and epidemiological characteristics at the individual or population level, and population level outcomes, such as STI prevalence, can be measured from the model output. Details of the model and how events are scheduled are given in the Supplementary Material Sections S.0-

\section{S.4.}

After Chick et al [15], concurrency in the simulated network was controlled by varying a concurrency parameter $\theta_{g}$, a real number between 0 and 1 which is specific to gender $g$. The role of $\theta_{g}$ in partnership formation is described in detail in the Supplementary Material Section S.2. $\theta_{g}{ }^{p}$ can be thought of as the probability that a person with $p$ current partners can take another partner, where $p$ is a non-negative integer. We defined $0^{0}$ to be equal to one. Therefore when we set $\theta_{g}$ to be equal to one, the value of $\theta_{g}{ }^{p}$ is equal to one regardless of the value of $p$, so the probability that a simulated individual can take another partner is unchanged for any number of current partners. If $\theta_{g}$ is less than one the probability that a simulated individual can take another partner decreases with increasing numbers of partners. If we set $\theta_{g}$ to be zero then simulated individuals can only take one current partner and therefore behave monogamously. Balancing the number of partnerships acquired by males and females followed a method proposed by Hallett et al [16].

\section{Scenarios}

We modelled two pairs of scenarios for the sexual network:
1. Lower level of concurrency
a) polygyny 


\section{b) gender-symmetry}
2. Higher level of concurrency
a) polygyny
b) gender-symmetry

All four scenarios were constructed to simulate the same level of sexual activity, measured by the same per-capita mean annual partnership incidence, and the same per-capita mean annual number of sex acts. The (a)-(b) pairs have the same level of concurrency, measured, after Morris and Kretzschmar [6], by $\kappa$, the average number of concurrent partnerships per partnership in the simulated population. To measure $k$ at a point in time, we summed, over all partnerships in the network at that point, the number of other partnerships that partnership was concurrent with (i.e. had a partner in common with). This number was divided by the total number of partnerships in the population at that time to give an average number of concurrent partnerships per partnership. If all individuals in a population are monogamous then the number of concurrent partnerships is zero for all partnerships, and thus $k=0$. If one or both of the genders are not monogamous then the number of concurrent partnerships per partnership increases and $k>0$.

The infections mimicking HSV-2 and HIV were introduced separately onto each of these four scenarios of the sexual networks, and therefore we simulated eight scenarios in total.

\section{Demography}

We simulated a population of 1000 males and 1000 females. The birth rate was 0.05 per woman per year for women over 20 years of age. Individuals become sexually active at age 20 , remain sexually active for 40 years, and then die at age 60 . In the absence of HIVrelated mortality, population size was approximately constant.

\section{Behaviour}


In all scenarios the mean incidence rate of new partnerships was 0.15 per person per year. The mean per-capita number of sex-acts per year was 35 in all scenarios (averaging over all members of the population, including those not in partnerships). In the polygyny scenarios, the value of $\theta$ for males $\left(\theta_{m}\right)$ was 1 and the value of $\theta$ for females $\left(\theta_{f}\right)$ was 0 . In the gendersymmetric scenarios, $\theta_{m}=\theta_{f}=\theta$. The values of $\theta$ were found by fitting the model to the desired values of partnership incidence rate, sex-act rate, and $k$ as described in section S.5 of the Supplementary Material. The higher concurrency scenarios $2 \mathrm{a}$ and $2 \mathrm{~b}$ had a longer mean partnership duration (6.5 years) and a higher $k(0.8)$ than the lower concurrency scenarios (duration $=2.5$ years and $k=0.4$ ). See Table S.6 and S.7 in the supplementary material for details of all parameter values.

The behavioural characteristics of the simulated network were found to stabilise by 50 years for all scenarios, so STIs were introduced at year 50 .

\section{Infection}

We simulated two long duration STIs. We first simulated HSV2 because this infection does not alter the structure of the sexual network by causing death and therefore the results from these scenarios are easier to interpret. We then repeated the scenarios with a second infection to mimick HIV by causing death. For simplicity and to allow easier comparison with the results for the non-fatal HSV2 infection, the same transmission probabilities were also assumed for the 'HIV-like' infection. HIV treatment was not modelled.

In year 50 we separately introduced these two infections onto the simulated networks described above. $1 \%$ of individuals were randomly selected for infection. After introduction, the model was run for a further 100 years for HSV2 to allow an endemic prevalence to be reached, and 30 years for HIV, approximating the time HIV has been spreading widely in many sub-Saharan Africa countries. 
In line with earlier modelling studies of HSV2 transmission in sub-Saharan Africa, for simplicity the simulated natural history of HSV2 was categorised into three stages: 'primary', 'middle', and 'late' [17-20]. Per-contact male-to-female (MtoF) transmission probabilities for both HIV and HSV2 were assumed to be twice those for female-to-male [21]. Per-contact HSV2 transmission probabilities were assumed to be highest during the 'primary' stage (MtoF=0.29) and lower during the 'middle' stage (MtoF=0.015) [22]. We assumed no HSV2 transmission during the 'late' stage. The durations of the STI stages were modelled as Weibull distributions with shape parameter 2, and mean stage durations of 1 month, 10 years and lifelong, respectively. Peaked distributions such as Weibull have been shown to provide a better fit than exponential distributions, for example the time from infection to death for HIV [23]. However, after around 10.1 years [24], individuals with the 'HIV-like' infection were simulated to die, rather than entering a non-infectious 'late' stage as for HSV2.

\section{Outcomes}

The current (instantaneous) partnership network was analysed because polygyny is defined on current partnership status rather than cumulative partnership status. To illustrate the differences between the simulated networks, in addition to network characteristics described above, for each scenario at year 50 we report the mean size of the largest connected group of individuals (component) in the network and the mean component size distribution. We selected, at random, one of the model iterations in which the observed largest component size was equal to this mean (to the nearest integer), then selected, at random, one of the largest components in this iteration to illustrate a typical 'largest component' in each scenario. The mean distribution of the number of current partners is also shown.

Mean prevalence over time and $95 \%$ confidence intervals for the mean were calculated based on 1000 simulation runs. The relative difference in prevalence was calculated 100 
years after introduction for HSV2 and 30 years after introduction for HIV. Confidence intervals for the relative difference were calculated by taking a log-transform of the ratio [25]. For comparison with the HIV-like infection, we also calculated results at 30 years for the HSV2 infection.

\section{Results}

\section{Behavioural characteristics of the simulated scenarios}

The actual outputs of the model (given in full in section S.6 of the supplementary material) agreed with the intended behavioural characteristics as described in the methods. The simulated level of sexual activity was constant in all scenarios: the mean annual partnership incidence per person was 0.15 and the mean annual number of sex-acts per person was 35 . The mean number of concurrent partnerships per partnership, $k$, was 0.4 in the lower concurrency scenarios and 0.8 in the higher concurrency scenarios.

Figure 1 (left) shows the component size distributions in the four scenarios. The component size distribution is fairly similar in the polygyny and symmetry scenarios, particularly at the lower concurrency level. Reniers et al proposed that, despite the same overall level of sexual activity and concurrency, polygyny prevented the formation of larger groups of individuals connected by partnerships compared to gender-symmetry in concurrency. We see this effect, particularly at higher concurrency. In the lower concurrency scenarios the mean size of the largest component was 4.4 in the polygyny scenario and 5.5 in the symmetry scenario. In the higher concurrency scenarios these figures are 6.1 and 10.1 . Differences in the structure of the typical largest component from the networks used can be seen in Figure 1 (middle and right). Longer chains can form in the symmetry scenarios, but under polygyny the longest chain is of length 2.

[Figure 1 about here] 
The mean number of current partners per person was the same in each gender and in each polygyny-symmetry pair $(0.35$ in the lower concurrency scenarios and 0.80 in the higher concurrency scenarios). Figure 2 shows the instantaneous mean partnership distribution for the four scenarios. As expected polygyny increased heterogeneity in numbers of current partners in males and decreased heterogeneity in current partners in women, compared to gender-symmetry in concurrency.

[Figure 2 about here]

\section{Infection prevalence}

Mean infection prevalence was significantly lower in polygyny scenarios compared to symmetric concurrency scenarios for both HSV2 and HIV at both concurrency levels (Figure 3).

[Figure 3 about here]

HSV2

After 100 years, in the lower concurrency scenarios the mean prevalence was $6.3 \%(95 \%$ confidence interval= 6.0-6.5) in the gender-symmetric concurrency scenarios and $5.1 \%(4.9$ 5.3) in the polygyny scenarios (Figure 3). The relative reduction in mean prevalence was $19 \%(14.6-22.9)$. In the higher concurrency scenarios, the mean prevalence was $7.2 \%(7.0-$ 7.5) in the gender-symmetric concurrency scenarios and $5.8 \%(5.6-6.0)$ in the polygyny scenarios. The relative reduction in mean prevalence was $20 \%(15.8-23.1)$.

As a comparison with the HIV-like infection, we also present the results after 30 years. In the lower concurrency scenarios the mean prevalence was 5.0\% (95\% confidence interval=4.9- 
5.1) in the gender-symmetric concurrency scenarios and $4.5 \%(4.4-4.6)$ in the polygyny scenarios (Figure 3). The relative reduction in mean prevalence was $11 \%(7.7-13.6)$. In the higher concurrency scenarios, the mean prevalence was $6.3 \%(6.2-6.4)$ in the gendersymmetric concurrency scenarios and $5.5 \%(5.4-5.6)$ in the polygyny scenarios. The relative reduction in mean prevalence was $13 \%(10.1-15.5)$.

HIV

After 30 years, in the lower concurrency scenarios the mean prevalence was $2.7 \%(2.6-2.8)$ in the gender-symmetric concurrency scenarios and $2.3 \%(2.3-2.4)$ in the polygyny scenarios (Figure 3). The relative reduction in mean prevalence was $14 \%(10.2-17.4)$. In the higher concurrency scenarios, the mean prevalence was $4.0 \%(3.9-4.1)$ in the gender-symmetric concurrency scenarios and 3.7\% (3.6-3.9) in the polygyny scenarios. The relative reduction in mean prevalence was $8 \%(4.5-11.4)$. The impact on HIV on the network characteristics after 30 years was small (see section S.8 in supporting material).

\section{Discussion}

The mean prevalence of both infections was significantly lower in simulated populations where only one gender practises concurrency compared to those where both genders practise concurrency. We compared simulated populations in which the mean rate of new partnerships per person, the mean number of sex-acts per person, and the mean number of concurrent partnerships per partnership, $\kappa$, was the same, so this difference was not attributable to a differing overall level of sexual activity or overall level of concurrency between the populations, but how polygyny caused partnerships to be distributed within these simulated populations.

The mean size of the largest component was higher in the symmetry scenarios, but the overall component size distributions were fairly similar. However the structure of the largest 
components is different: markedly longer partnership-chains were observed in the symmetry scenarios (Figure 1). Under polygyny, an STI cannot travel further than from a woman to a man and his immediate partners until one of the partnerships dissolves. This constraint is removed when both genders have concurrent partnerships.

It has been shown here that infection prevalence can be lower in polygynous populations than in populations where concurrency is symmetric. However it does not prove that the structural differences in the network drive the negative association described in the study by Reniers and Watkins [9]; as the authors suggest, this could also be due to lower coital frequency in polygynous unions, or an artefact of the ecological inference fallacy. In addition, models are necessarily simplifications of reality and the simulations used in this study are much simpler than real populations in terms of demography, sexual behaviour and epidemiology. For convenience simulated fertility rates were lower than commonly observed in sub-Saharan Africa to allow the population size to be kept constant. In order to compare the high and low concurrency scenarios we required the overall level of sexual activity to be the same. Constraining the parameters in this way necessitated a high proportion $(70 \%$, see Figure 2) of the population to not be in partnership at a point in time in the low concurrency scenarios. The population size was small and homogeneous in sexual behaviour within genders. Only heterosexual partnerships were modelled, and we modelled random partnership formation by age. To ensure the results were easier to interpret, other known behavioural and biological determinants of transmission (such as casual partnerships, sex work and STI co-factors for HIV transmission [26]) were not modelled. As a result we simulated lower HIV and HSV2 prevalences than are typically observed in sub-Saharan Africa populations $[27,28]$. Our assumed transmission probabilities for the 'HIV-like' infection were much higher (around 10 times) than observed $[29,30]$ to allow us to more easily compare the effect of an STI that leads to infection-related death to the effects of an 
'HSV2-like' infection. Further work is required to explore whether our results are robust to modelling more realistic simulated populations and infection characteristics.

Concurrency is commonly thought to increase the prevalence of HIV [5]. In contrast, this study tends to support the hypothesis from ecological studies that polygyny, a specific form of institutionalised concurrency, may be protective against HIV at the population level $[9,10]$. A recent Demographic and Health Survey working report of an analysis of data from 18 counties in Africa found that polygyny accounted for a substantial proportion (between 11\% and $21 \%$ ) of concurrent relationships in all countries [31], so making a distinction between polygyny and other types of concurrent relationships could be important for understanding differing epidemiological trends and implementing interventions that seek to reduce levels of concurrency [7].

Word count (main text): 2757

\section{Competing interests}

None

\section{Funding}

This work was supported by the Wellcome Trust (RGW, RC and RJH [GR078499MA]), the UK Medical Research Council (RGW, KOB, RB, TE, RJH and LAS), the Bill and Melinda Gates Foundation (RGW), the EU FP7 EPIWORK (231807) (RGW) and GlaxoSmithKline (SS). The funders had no involvement in the design, collection, analysis or interpretation of the data, in writing the report or in the decision to submit.

\section{Contributors}


RGW and SS designed the study. SS, KOB and RGW performed the mathematical modelling. TE, RB, KOB, RGW and LAS, designed and wrote the mathematical model. SS and RGW wrote the manuscript with contributions from all authors. All authors approved the final version of the manuscript.

\section{Copyright License Statement}

The Corresponding Author has the right to grant on behalf of all authors and does grant on behalf of all authors, an exclusive licence (or non exclusive for government employees) on a worldwide basis to the BMJ Publishing Group Ltd to permit this article (if accepted) to be published in STI and any other BMJPGL products and sub-licences such use and exploit all subsidiary rights, as set out in our licence

http://group.bmi.com/products/journals/instructions-for-authors/licence-forms

\section{Key messages}

- Concurrency is thought to fuel HIV epidemics but ecological data demonstrate that HIV prevalence is lower in populations with more polygyny.

- One causal explanation for this finding is that polygyny prevents the formation of large groups of individuals connected by partnerships.

- This modelling study tested this hypothesis and showed that the prevalence of infections like HSV2 and HIV was lower in networks modelling polygyny.

- Making a distinction between polygyny and other types of concurrency could be important for implementing interventions that seek to reduce levels of concurrency to reduce HIV transmission. 


\section{References}

1 UNAIDS 2009 AIDS epidemic update. UNAIDS, Geneva 2009.

2 Halperin DT, Epstein H. Concurrent sexual partnerships help to explain Africa's high HIV prevalence: implications for prevention. Lancet. 2004;364(9428):4-6.

3 Mah TL, Halperin DT. Concurrent Sexual Partnerships and the HIV Epidemics in Africa: Evidence to Move Forward. AIDS Behav. 2008.

4 Morris M, Kretzschmar M. Concurrent partnerships and the spread of HIV. AIDS. 1997;11(5):641-8.

5 Morris M, Kretzschmar M. A microsimulation study of the effect of concurrent partnerships on the spread of HIV in Uganda; 2000. Math Popul Stud 2000;8:109-133

6 Doherty IA, Shiboski S, Ellen JM, Adimora AA, Padian NS. Sexual Bridging Socially and Over Time: A Simulation Model Exploring the Relative Effects of Mixing and Concurrency on Viral Sexually Transmitted Infection Transmission. Sex Transm Dis. 2006 Jun;33(6):368-73.

7 Lurie MN, Rosenthal S. Concurrent Partnerships as a Driver of the HIV Epidemic in SubSaharan Africa? The Evidence is Limited. AIDS Behaviour 2010;14(1):17-24

8 Kretzschmar M, White RG, Carael M. Concurrency is more complex than it seems Editorial. AIDS. 2010;16;24(2):313-5.

9 Reniers G, Watkins S. Polygyny and the spread of HIV in Sub-Saharan Africa: a case of benign concurrency. AIDS. In press.

10 Reniers G, Tfaily R. Polygyny and HIV in Malawi. Demogr Res. 2008;19:1811-30.

11 Rothman KJ, Greeenland S. Modern Epidemiology. 2nd Edition. Philadelphia: Lippincott Williams \& Williams 1997.

12 Grimm V, Railsback SF. Individual-based Modeling and Ecology. Princeton: Princeton University Press 2005.

13 Van der Ploeg CPB, Van Vliet C, De Vlas SJ, O. N-AJ, Lieve F, J VOG, et al. STDSIM: A microsimulation model for decision support in STD control. Interfaces. 1998;28:84-100.

14 Brown R. Calendar Queues: A Fast 0(1) Priority Queue Implementation for the Simulation Event Set Problem. Communications of the ACM 1988;31(10):1220-7.

15 Chick SE, Adams AL, Koopman JS. Analysis and simulation of a stochastic, discreteindividual model of STD transmission with partnership concurrency. Math Biosci. 2000 Jul;166(1):45-68.

16 Hallett TB, Gregson S, Lewis JJ, Lopman BA, Garnett GP. Behaviour change in generalised HIV epidemics: The impact of reducing cross-generational sex and delaying age at sexual debut. Sex Transm Infect. 2007 Feb 21;83:i50-i4.

17 Freeman E, Orroth K, White RG, Glynn JR, Bakker R, Boily M-C, et al. The proportion of new HIV infections attributable to HSV-2 increases over time: simulations of the changing role of sexually transmitted infections in sub-Saharan African HIV epidemics. STI. 2007;83:i17-i24.

18 Orroth KK, Freeman E, Bakker R, Buve A, Glynn J, Boily M-C, et al. Understanding differences across the contrasting epidemics in East and West Africa: results from a simulation model of the Four Cities Study. STI. 2007;83:i5-i16.

19 Freeman EE, White RG, Bakker R, Orroth KK, Weiss HA, Buve A, et al. Population-level effect of potential HSV2 prophylactic vaccines on HIV incidence in sub-Saharan Africa. http://dx.doi.org/10.1016/j.vaccine.2008.11.074 Vaccine. 2009;27:940-6.

20 White RG, Freeman EE, Orroth KK, Bakker R, Weiss HA, O'Farrell N, et al. Populationlevel effect of HSV-2 therapy on the incidence of HIV in sub-Saharan Africa. Sex Transm Infect. 2008;84(S2):12-8.

21 Mertz GJ, Ashley R, Burke RL, Benedetti J, Critchlow C, Jones CC, et al. Double-Blind, placebo-controlled trial of a herpes simplex virus type 2 glycoprotein vaccine in persons at high risk for genital herpes infection. J Infect Dis. 1990;161:653-60.

22 Corey L, Adams HG, Brown ZA, Holmes KK. Genital herpes simplex virus infections: clinical manifestations, course, and complications. Ann Intern Med. 1983;98(6):958-72. 
23 CASCADE. Time from HIV-1 seroconversion to AIDS and death before widespread use of highly-active antiretroviral therapy: a collaborative re-analysis. Collaborative Group on AIDS Incubation and HIV Survival including the CASCADE EU Concerted Action. Concerted Action on SeroConversion to AIDS and Death in Europe. Lancet 2000;355(9210):1131-7

24 Todd J, Glynn JR, Marston M, Lutalo T, Biraro S, Mwita W, et al. Time from HIV seroconversion to death: a collaborative analysis of eight studies in six low and middleincome countries before highly active antiretroviral therapy. AIDS. 2007 Nov;21 Suppl 6:S5563.

25 Altman D, Machin D, Bryant T, Gardner S, eds. Statistics With Confidence. 2 ed: WileyBlackwell 2000.

26 Hayes RJ, Schulz KF, Plummer FA. The cofactor effect of genital ulcers on the perexposure risk of HIV transmission in sub-Saharan Africa. Review. J Trop Med Hyg. 1995;98(1):1-8.

27 Smith JS, Robinson NJ. Age-specific prevalence of infection with herpes simplex virus types 2 and 1: a global review. J Infect Dis. 2002 Oct 15;186 Suppl 1:S3-28.

28 Looker KJ, Garnett GP, Schmid GP. An estimate of the global prevalence and incidence of herpes simplex virus type 2 infection. Bull World Health Organ. 2008 Oct;86(10):805-12, A.

29 Wawer MJ, Gray RH, Sewankambo NK, Serwadda D, Li X, Laeyendecker O, et al. Rates of HIV-1 Transmission per Coital Act, by Stage of HIV-1 Infection, in Rakai, Uganda. J Infect Dis. 2005 May 1;191(9):1403-9.

30 Boily MC, Baggaley RF, Wang L, Masse B, White RG, Hayes RJ, et al. Heterosexual risk of HIV-1 infection per sexual act: a systematic review and meta-analysis of observational studies. Lancet Infect Dis. 2009 Feb;9(2):118-29.

31 Vinod M, Bignami-Van Assche S. Concurrent Sexual Partnerships and HIV Infection: Evidence from National Population-Based Surveys. DHS Working Papers No. 62. Calverton: Macro International Inc. 2009. 
Figure legends

Figure 1 Component size distribution and typical largest network component in each of the four scenarios

Figure 2 Distribution of number of current partners in simulated populations in each of the four scenarios

Figure 3 Impact of polygyny vs. gender-symmetric concurrency on mean prevalence of an HSV2-like and HIV-like infection over time. Dashed lines show 95\% confidence intervals for the mean 
口Polygyny $\mathbf{a}$ Symmetry
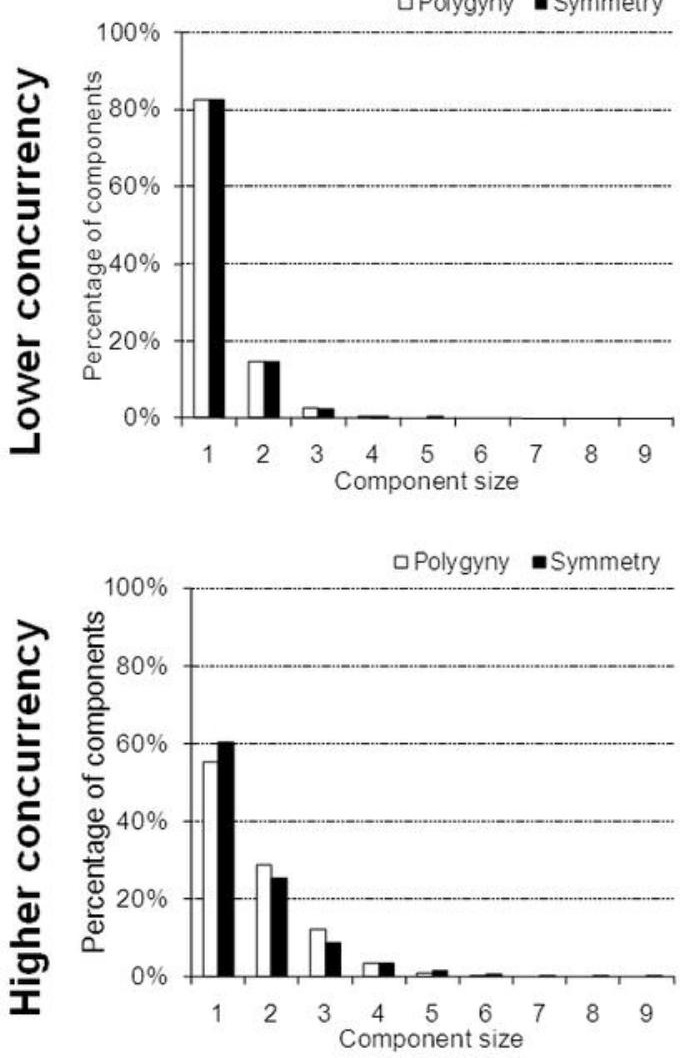

\section{Polygyny}

Symmetry
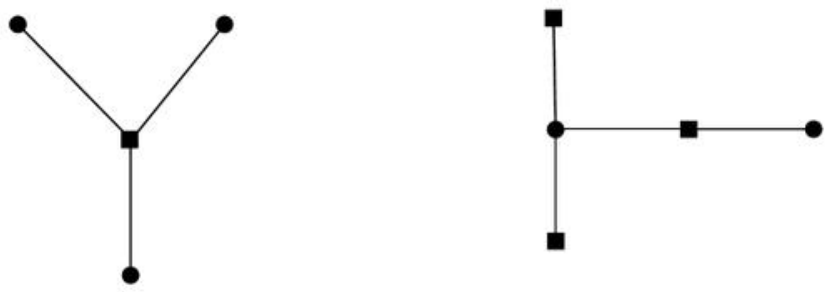

male

female

partnership

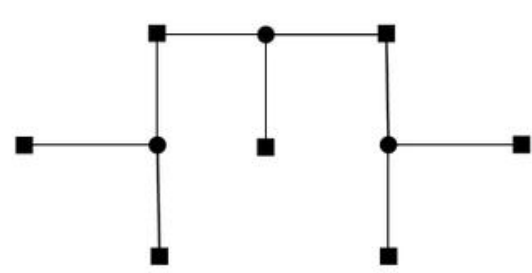




\section{Number of current partners}
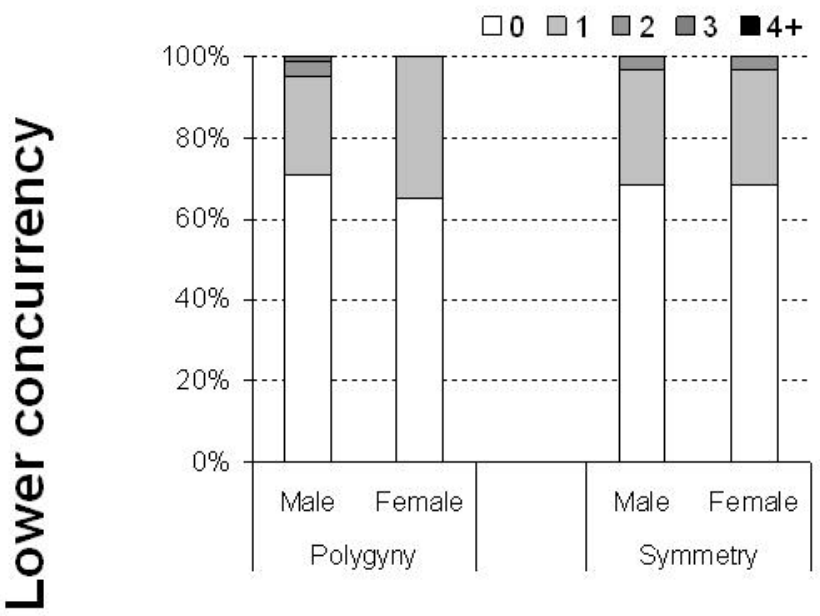

$\square 0 \square 1 \square 2 \square 3 \square 4+$
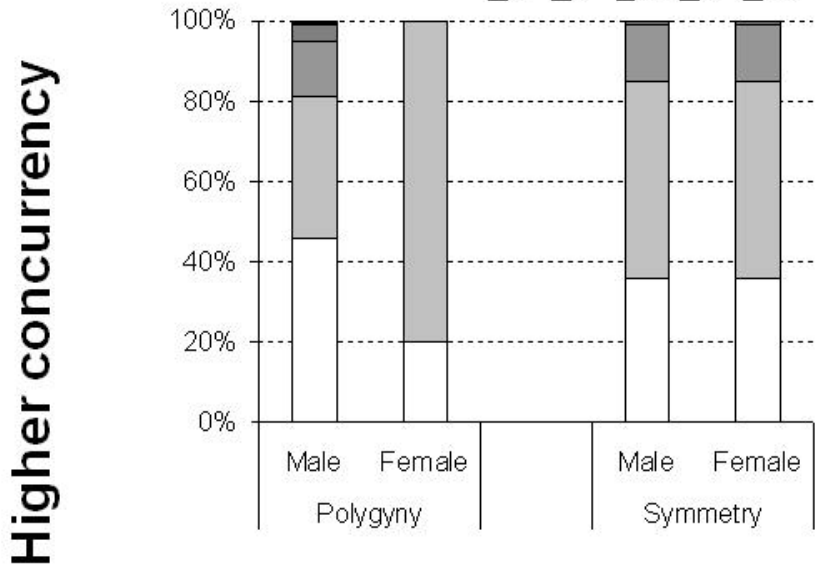


\section{Lower concurrency}
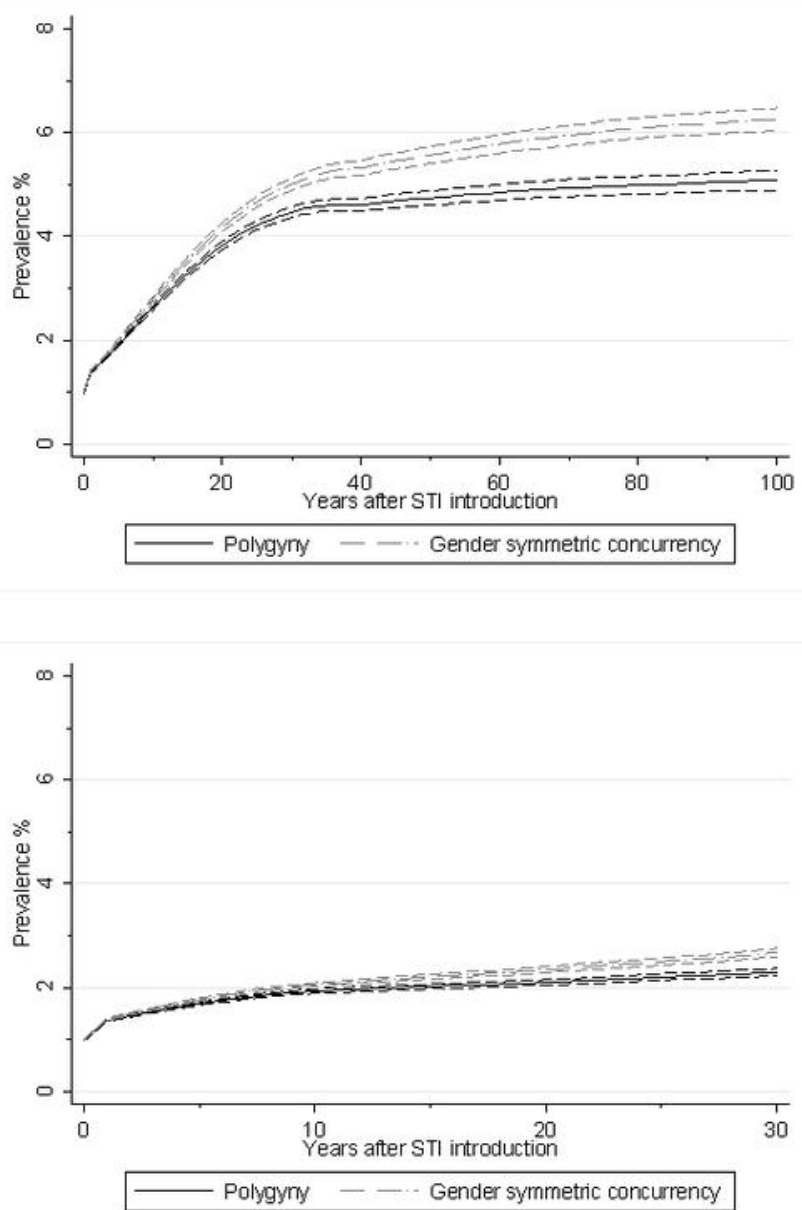
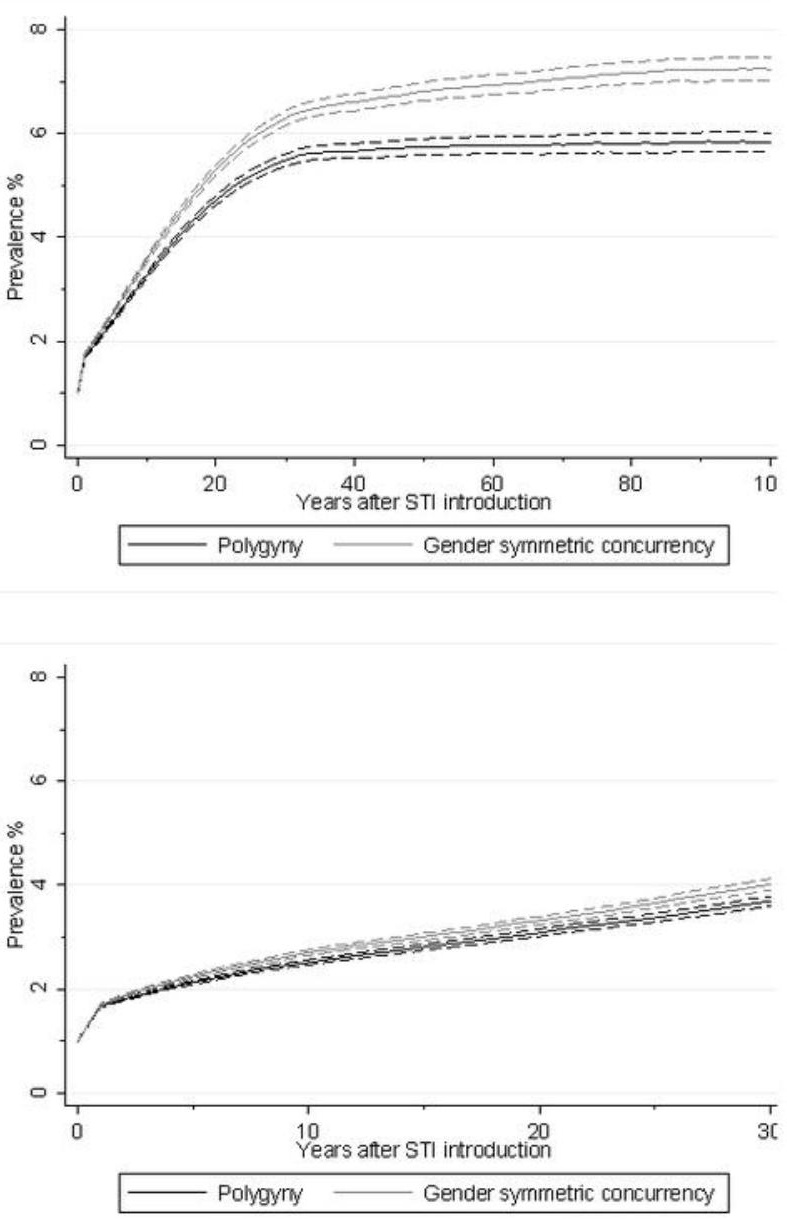